\title{
Investigation on combustion parameters of palm biodiesel operating with a diesel engine
}

\author{
M.H.M. Yasin ${ }^{1,}$, R. Mamat' ${ }^{2}$, A. Aziz ${ }^{2}$, A.F. Yusop ${ }^{2}$ and M.H. Ali ${ }^{1}$ \\ ${ }^{1}$ Department of Mechanical Engineering, Politeknik Kota Kinabalu, \\ 88450 Kota Kinabalu, Sabah, Malaysia \\ *Email: hafizil@polikk.edu.my \\ Phone: +60137114669; Fax no: 088-499960 \\ ${ }^{2}$ Faculty of Mechanical Engineering, \\ Universiti Malaysia Pahang 26600 Pekan Pahang, Malaysia
}

\begin{abstract}
Biodiesel is a renewable and decomposable fuel which is derived from edible and nonedible oils. It has different properties compared to conventional diesel but can be used directly in diesel engines. Different fuel properties characterise different combustionphasing parameters such as cyclic variations of Indicated Mean Effective Pressure (IMEP) and maximum pressure (Pmax). In this study, cyclic variations of combustion parameters such as IMEP and Pmax were investigated using a multi-cylinder diesel engine operating with conventional diesel and palm biodiesel. The experiments were conducted using different engine loads; 20,40 , and $60 \%$ at a constant engine speed of $2500 \mathrm{rpm}$. The coefficient of variation (COV) and standard deviation of parameters were used to evaluate the cyclic variations of the combustion phasing parameters for the test fuels at specific engine test conditions. It was observed that palm biodiesel has lower COV IMEP compared to conventional diesel but is higher in COV Pmax at higher engine loads respectively. In addition, palm biodiesel tends to have a higher recurrence for the frequency distribution for maximum pressure. It can be concluded from the study that the fuel properties of palm biodiesel have influenced most of the combustion parameters.
\end{abstract}

Keywords: Combustion; palm biodiesel; IMEP; coefficient of variation; diesel engine

\section{INTRODUCTION}

Biodiesel is an alternative fuel derived from edible and non-edible oils through the transesterification process. Biodiesel can be used directly for the diesel engines with little or no modification aydin [1-6]. Some researchers investigated the effect of diluted biodiesel with conventional diesel in different proportions to reduce the density and viscosity when running with diesel engines [7-17]. At present, many studies are focussing on the performance and emission of biofuels under internal combustion engine conditions, production process of biofuels and effect of biofuels blends with conventional fuels. However, the fundamental combustion properties and chemical kinetic descriptions of biofuels are still under investigation. The composition of biodiesel is typically a combination of long chain fatty acid methyl esters (FAME) derived from vegetable oils or animal fats through the transesterification process. The transesterified fuels contain physical properties comparable to those of petroleum-based diesel fuels and are suitable to be used neat or in blends for diesel engines [18-20]. Among the main feedstocks for 
biodiesel production and testing are oilseeds including jathropa [21], palm oil [21], rapeseed [22], soybean [23] and animal fats [24].

Palm biodiesel has lucrative potentials and advantages to offer as it has similar characteristics with diesel fuels and is environmental-friendly [2, 25-28]. However, fuel physical factors that have been identified are higher viscosity, lower heating value, low volatility, poor atomization and higher oxygen content beside polyunsaturated characteristics [29,30]. The major problem of methyl or ethyl esters is its higher viscosity compared to fossilized fuel that requires more time to ignite. Different fuel properties and injection delay provide stimulating studies for the combustion cycle-to-cycle variations of diesel engines [31,32]. Several cycle-to-cycle pressure variation studies on different fuels; diesel, biodiesel, and gasoline operating with diesel engines were conducted to determine the definite combustion characteristics [33]. These arguments are based on the different types of fuel that reflected most of the assorted combustion characteristics to the similar diesel engine at the same operating condition. In addition, several identified parameters contribute to the cylinder pressure variations including the various total amount of air and fuel charge to the cylinder in each cycle, mixture motion variations within the cylinder and air charge content variations. In this study, palm biodiesel and conventional diesel as the reference fuels were tested in a diesel engine with a constant speed of $2500 \mathrm{rpm}$ at different engine loads; 20, 40, and 60\%. Combustion results were recorded for 200 consecutive cycles. The aim of this experimental study is to determine the coefficient of variation, frequency distributions for indicated mean effective pressure and frequency distributions for maximum pressure for the test fuels.

\section{EXPERIMENTAL SET UP}

The primary of the engine research facility is a Mitsubishi 4D68 multi-cylinder, fourstroke water-cooled diesel engine (Figure 1). This engine is naturally aspirated with its injection pressure is more or less set to 206 bars. Maximum power for the engine is 64.9 $\mathrm{kW}$ at the rated speed of $4500 \mathrm{rpm}$. More engine details are listed in Table 1 . The engine was coupled with a $150 \mathrm{~kW}$ eddy-current type water-cooled Dynalec dynamometer model ECB-200F SR 617 for the loading purposes.

Table 1. Specification for a diesel engine.

\begin{tabular}{lc}
\hline Description & Specification \\
\hline Number of cylinders & 4 in-line \\
Combustion chamber & Swirl chamber \\
Total displacement cm & $1.998 \mathrm{cc}(121.925 \mathrm{cu}$ in $)$ \\
Cylinder bore mm x Piston stroke mm & $82.7 \times 93$ \\
Bore/stroke ratio & 0.89 \\
Compression ratio & $22.4: 1$ \\
\hline
\end{tabular}

The first of four engine cylinders was mounted with a Kistler 6041A water-cooled Thermo Comp in-cylinder pressure transducer. A Kistler CAM crank angle encoder model 2613B1 was used to determine the crankshaft position within the combustion period and the piston continuous movements from the top dead centre (TDC) to the bottom dead centre (BDC). The temperatures for the engine monitoring including the intake manifold, exhaust extractors, ambient temperatures were obtained by thermocouples J-type and K-type. A DAQ card was used in the testing facilities which 
are Orion 1624 E-card installed on a DEWE-800 lab instrument with 16 slots for DAQ/PAD modules and 2 PCI slots. This card provides 16 simultaneous sampled differential channels at $200 \mathrm{kS} / \mathrm{s}$ each and 24-bit resolution. While Spectrum MI.3111 DAQ card with 12-bit resolutions simply provide a channel for Kistler crank angle encoder. Data acquired during the experiment was retrieved using software DEWESoft and DEWECa provided by DEWETRON.

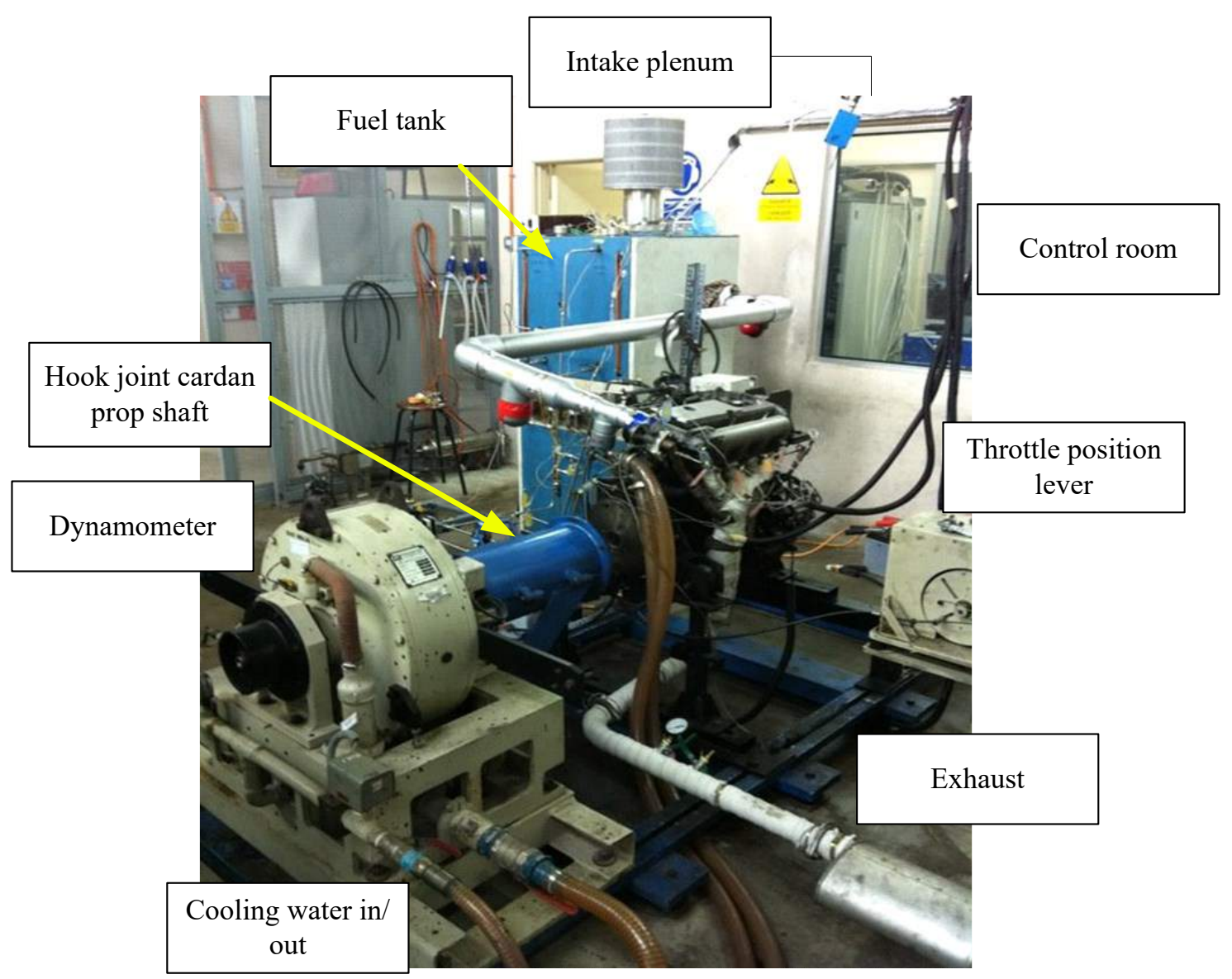

Figure 1. Test engine.

Figure 2 shows the schematic diagram engine experimental set up. A DEWECa combustion system was used for in-cylinder pressure measurement and recorded up to 1000 consecutive combustion cycles. Furthermore, the obtained combustion data at each operating test condition with different fuels were computed to determine the maximum cylinder pressure and indicate mean effective pressure (IMEP). Using these two parameters, the coefficient of variation $(\mathrm{COV})$ and frequency distributions at crank angle degree (CAD) are computed for analysing the cycle-to-cycle variation with the operating test fuels. The statistical computation was performed using Origin 8 software from OriginLab. In this study, the frequency distribution is calculated to arrange the values from the set of variables in the sample. As an example, the frequency distributions of maximum cylinder pressure (Pmax) and crank angle degree (CAD) are computed from the sample size which is 200 engine cycles. This represents the count of the repetitiveness of values within a specific size or particular group. While as for IMEP calculation, the pressure indication at each cylinder is the most accurate method of calculating IMEP. 
IMEP can be defined as a function of the indicated work output per unit swept volume. It is calculated as follows:

$$
I M E P=\frac{\sum_{i=1}^{\# c y l i n d e r s} \oint \frac{p \cdot d V}{V_{1}}}{\# c y l i n d e r s}
$$

where $p$ indicates the in-cylinder pressure, $V_{1}$ is one cylinder displacement and \# cylinders are number of cylinders.

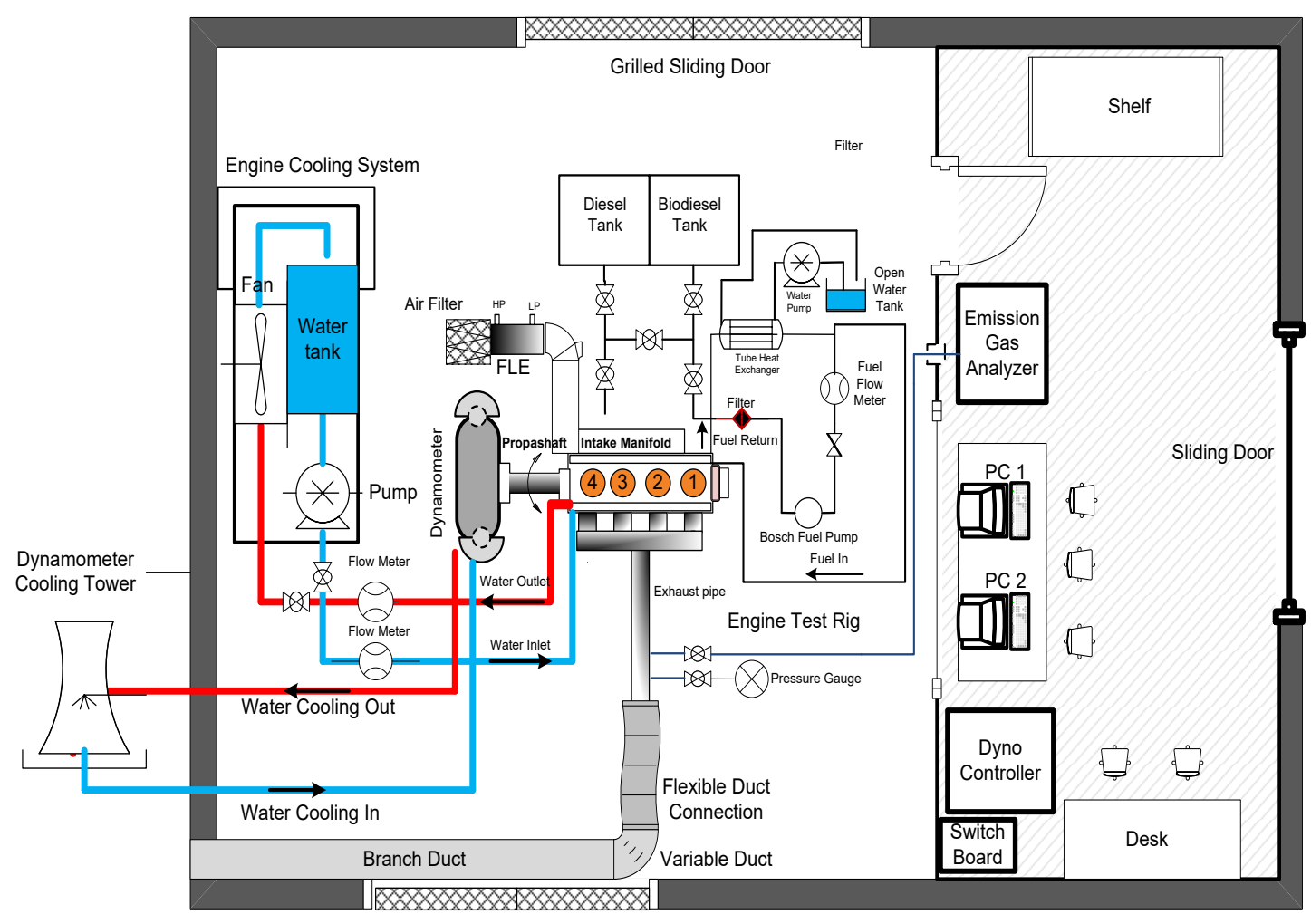

Figure 2. Schematic diagram engine experimental set up.

The coefficient of variation can be defined as computed relative standard deviation (RSD) that represents the ratio of the standard deviation to the mean, which is a standardized measure of dispersion for the mean of a frequency distribution or the variation of the data series. The formula is expressed as follows:

$$
\begin{gathered}
\overline{P_{\max }}=\frac{1}{n} \sum_{i=1}^{n} P_{\max , i} \\
\sigma_{P_{\max }}=\sqrt{\frac{\sum_{i=1}^{n}\left(\overline{P_{\max }}-P_{\max }\right)^{2}}{n-1}} \\
\operatorname{COV}_{P_{\max }}=\frac{\sigma_{P_{\max }}}{\bar{P} \max _{\max }}
\end{gathered}
$$

Besides applying Eq. (1-3) on Pmax calculation, these three equations are similarly applied to the IMEP statistical computation. 


\section{Fuel Preparation and Analysis}

There were two types of fuel in this study which includes palm biodiesel (B100) and conventional diesel as a reference fuel as presented in Figure 3. Conventional diesel was purchased from the domestic petrol station while palm biodiesel was procured from the biodiesel producer. Figure 4 illustrates different analytical apparatus to measure the fuel properties for the test fuels. All the test methods are conformed to the strict ASTM procedures as recommended by manufacturers. Those tests were conducted at controlled room temperature, pressure and relative humidity to ensure that the result is not influenced by environmental errors.

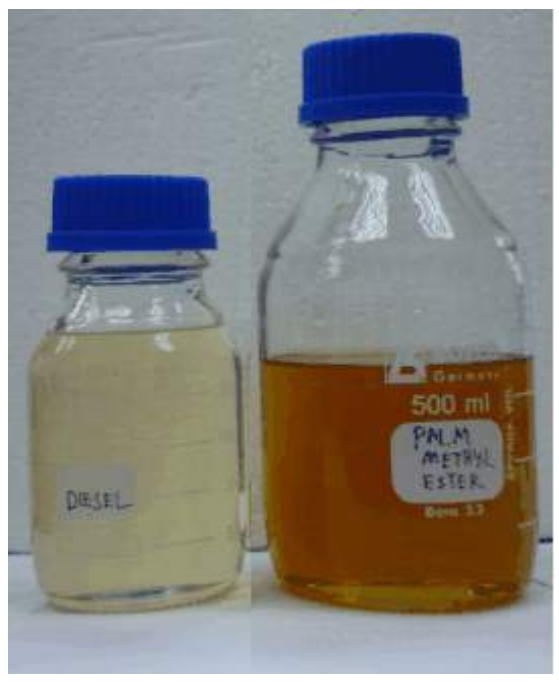

Figure 3. Conventional diesel and palm biodiesel samples.

Table 2 presents the results of palm biodiesel and conventional diesel fuel properties testing through experiments. The testing was repeated five times and carefully recorded by the digital apparatus. It can be seen from the table that the fuel properties are greatly influenced by the concentration of biodiesel when compared to conventional diesel. It is obviously configured that palm biodiesel has different characteristics when being compared to conventional diesel.

Table 2. Fuel properties for conventional diesel and palm biodiesel [34].

\begin{tabular}{lcc}
\hline \multicolumn{1}{c}{ Properties } & Conventional diesel & Palm biodiesel \\
\hline Heat value $\left(\mathrm{MJ} \mathrm{kg}^{-1}\right)$ & 45.28 & 41.3 \\
Cloud point $\left({ }^{\circ} \mathrm{C}\right)$ & 18 & 14 \\
Density $@ 15^{\circ} \mathrm{C}\left(\mathrm{kg} / \mathrm{m}^{3}\right)$ & 853.8 & 867 \\
& 93 & 165 \\
Flash point $\left({ }^{\circ} \mathrm{C}\right)$ & 12 & 15 \\
Pour point $\left({ }^{\circ} \mathrm{C}\right)$ & 54.6 & 67 \\
Cetane Number & 2.6 & 4.53 \\
Kinematic Viscosity at $40 \mathrm{C}\left(\mathrm{mm}^{2} / \mathrm{s}\right)$ & 12 & 6 \\
Sulfur content $(\mathrm{mg} / \mathrm{kg})$ & $<0.01$ & $<0.01$ \\
Carbon residue content $(\mathrm{wt} . \%)$ & &
\end{tabular}




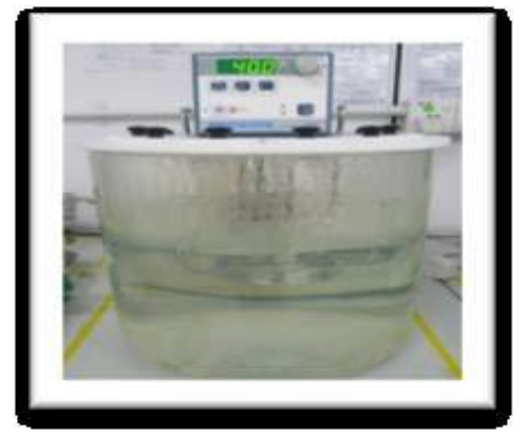

(a)

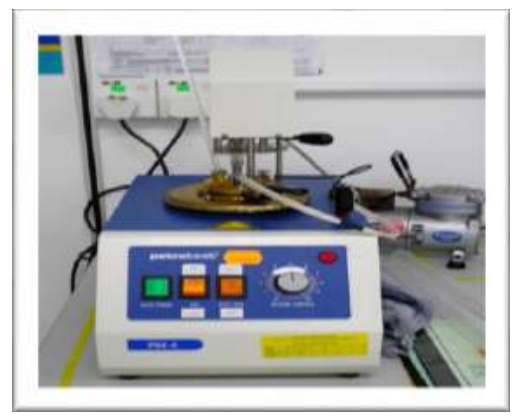

(c)

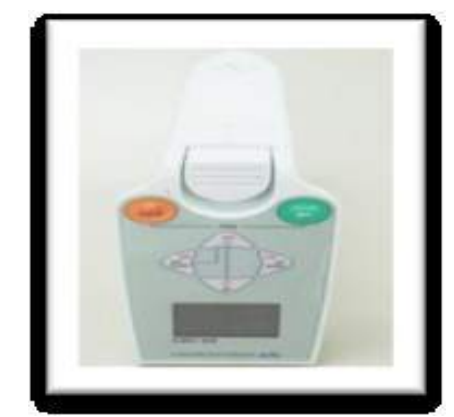

(b)

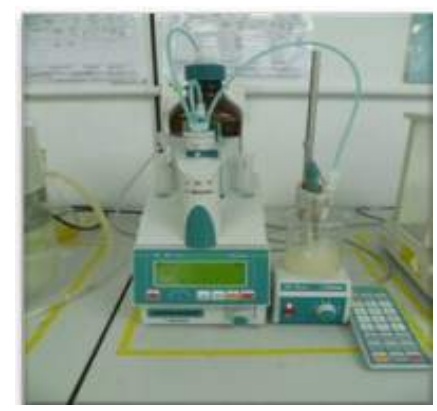

(d)

Figure 4. Analytical instruments used to measure fuel properties; (a) Viscosity bath, (b) Density meter, (c) Pensky-Martens Closed Tester, (d) Acid value \& acidity tester.

\section{RESULTS AND DISCUSSION}

The in-cylinder pressure measurement recording for the test fuels was determined for the 200 cycles with a sampling rate that corresponds to $1^{\circ} \mathrm{CA}$. The indicated cylinder pressure has been averaged by taking a number of 200 combustion cycles. Figure 5 presents the coefficient of variations for maximum cylinder pressure, indicated mean effective pressure and frequency distributions of 5\% mass fraction burned, 10\% MFB,50\% MFB and $90 \%$ MFB of two fuels; palm biodiesel and conventional diesel at three different engine loads with a constant engine speed of $2500 \mathrm{rpm}$. It can be noticed from these figures that the COV IMEP is satisfying the diesel engine condition under various operating conditions. It is observed in Figure 5(a) and 5(b) that COVs for Pmax are relatively small $(<\%)$ for both test fuels and COV for frequency distributions of $5 \% \mathrm{MFB}$, $10 \%$ MFB, 50\% MFB and 90\% MFB are also small for conventional diesel and palm biodiesel. These results are parallel with previous studies on engine cycle-to-cycle variation related to biodiesel fuel properties $[35,36]$. A drawback of the conventional diesel engine is when the COV IMEP exceeds $10 \%$, drivability problems in vehicles could arise. Since it could affect the engine drivability, the need to study the engine cyclic variations is compulsory especially when involving the combustion phasing parameters. It is found in the figure that the test engine operating with conventional diesel has higher COV IMEP as compared to the engine operating with palm biodiesel. 


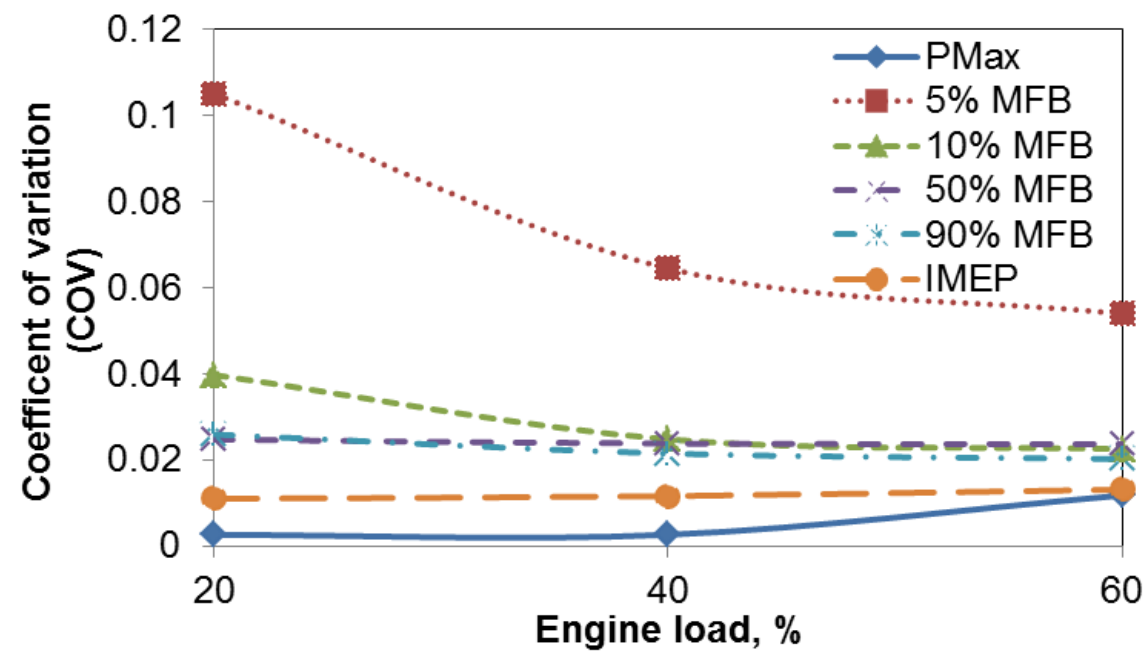

(a)

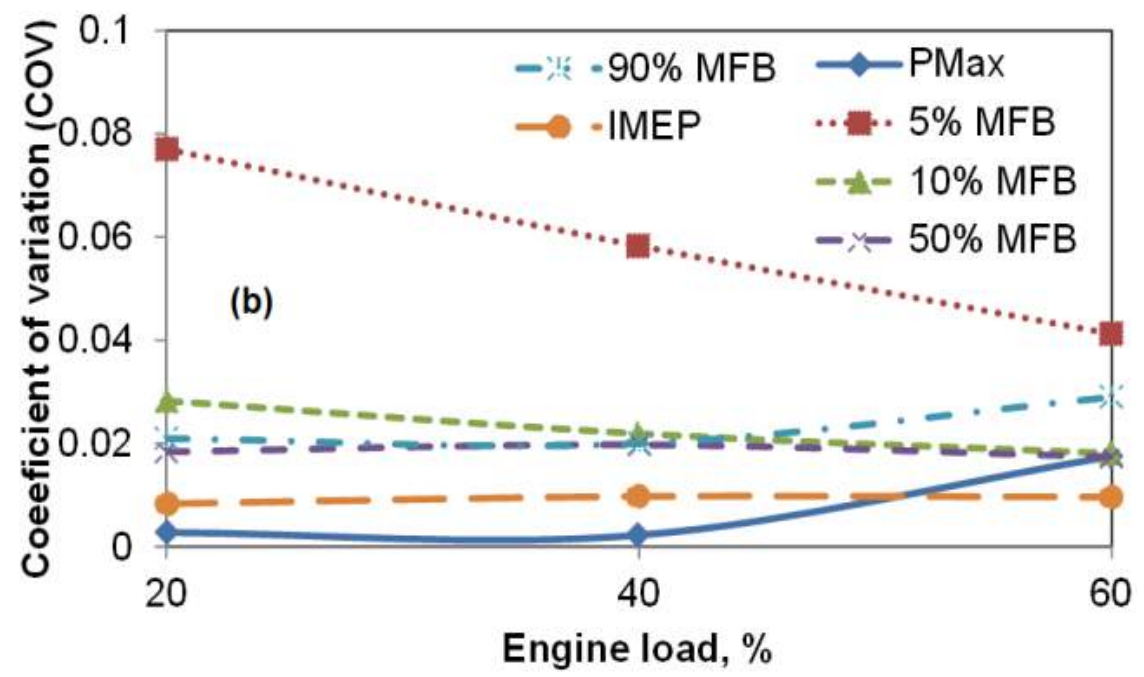

Figure 5. Coefficient of Variation (COV) of IMEP, Pmax and MFB for (a) conventional diesel and (b) palm biodiesel corresponding to the engine loads.

Frequency distributions of maximum cylinder pressure for diesel and palm biodiesel were illustrated in Figure 6. It is apparent that the frequency distributions of Pmax are taken from the data of 200 consecutive cycles with the engine operating at specific engine loads; 20, 40 and $60 \%$. It can be noticed from these figures that there is an increase in the maximum cylinder pressure corresponding to the increase in engine loads for the test fuels. This condition is parallel with the previous cycle-to-cycle variation studies conducted by other researchers on biodiesel testing [36-38]. It can be noticed from the figure that the frequency distribution values for palm biodiesel is higher as compared with conventional diesel for engine loads of 20, 40 and $60 \%$ at a constant engine speed of $2500 \mathrm{rpm}$. Adjacent scatters for Pmax are found at 20 and $40 \%$ engine loads for both test fuels. However, extensive frequency distributions occur at $60 \%$ engine load for both test fuels. It is found that the dispersion frequency distributions for maximum cylinder pressure at higher load may be attributed to the inconsistency intake charge during fuel combustion [39]. 


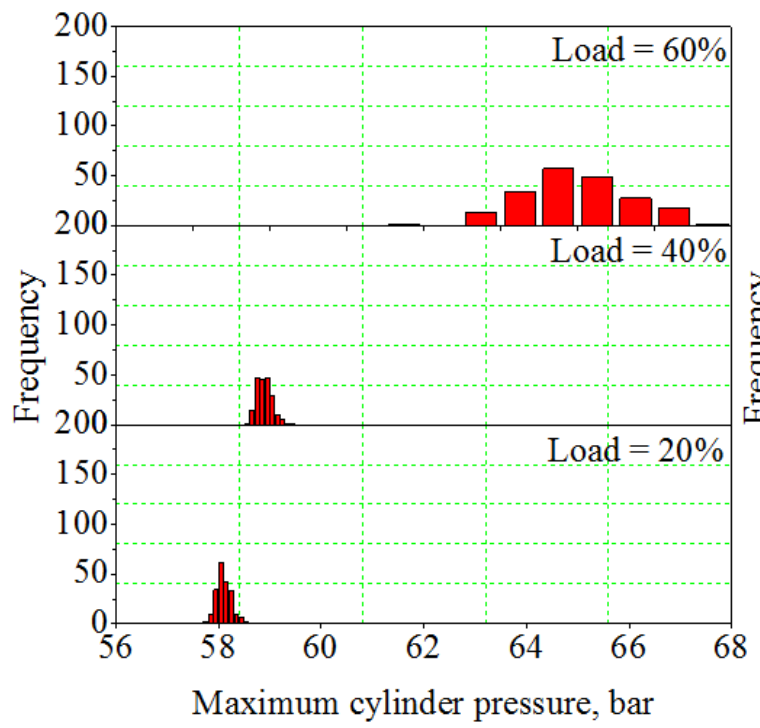

(a)

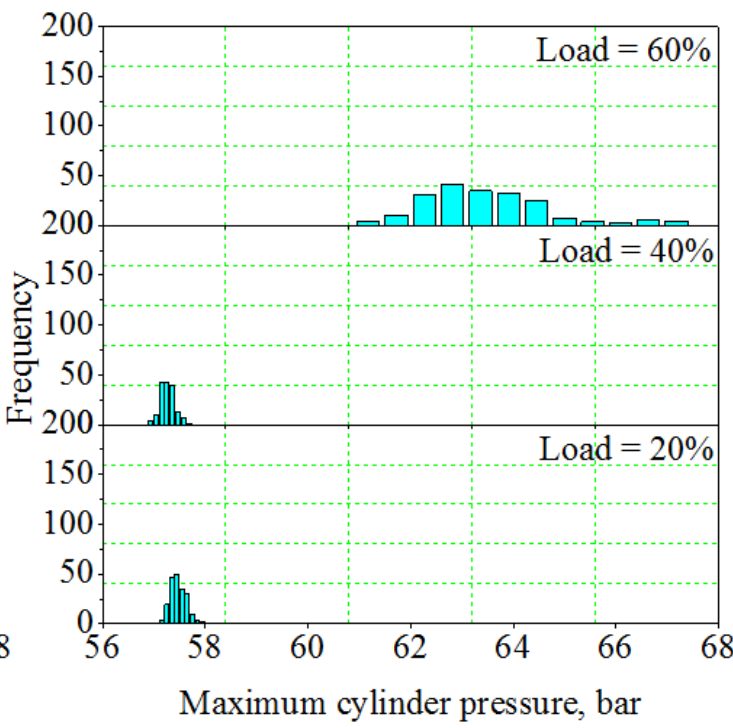

(b)

Figure 6. Frequency distributions for (a) conventional diesel and (b) palm biodiesel corresponding to maximum cylinder pressure, Pmax.

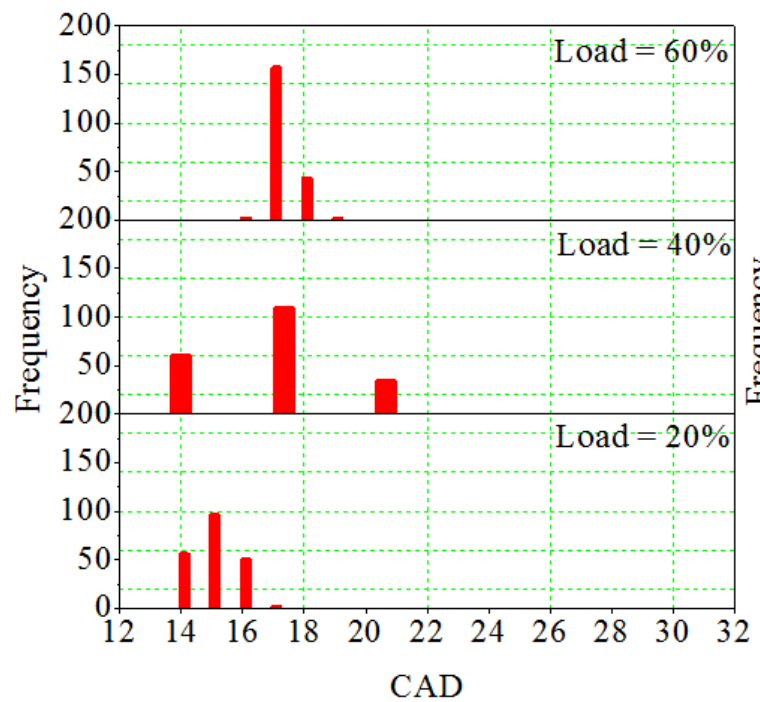

(a)

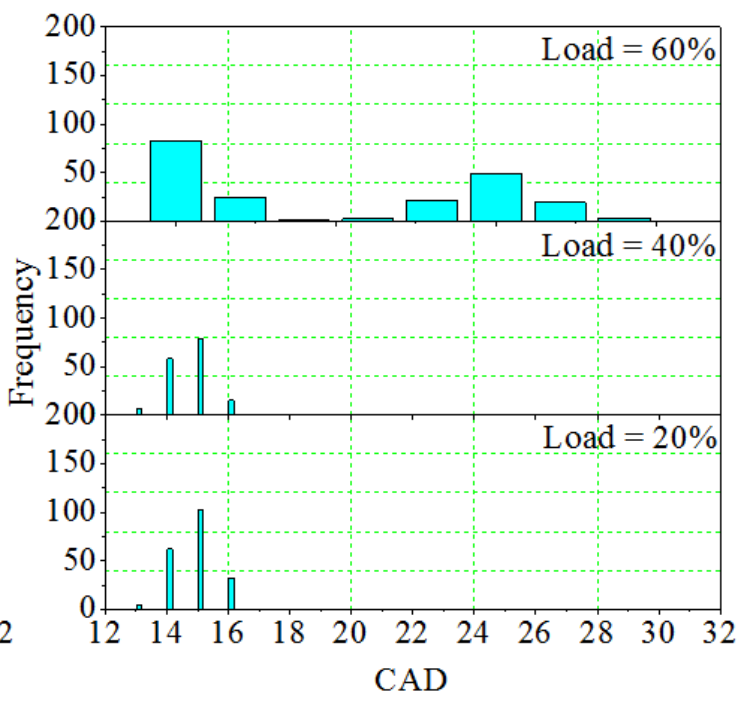

(b)

Figure 7. Frequency distributions of maximum cylinder pressure, Pmax for (a) conventional diesel and (b) palm biodiesel corresponding to crank angle degree, CAD.

Figure 7 shows the frequency distributions of the maximum cylinder pressure corresponding to the crank angle degree for conventional diesel and palm biodiesel for 200 cycles. It is observed from these figures that the Pmax frequency distributions at crank angle degree for conventional diesel has more concentration which is between 14 CAD and 22 CAD compared to palm biodiesel (13 CAD to $28 \mathrm{CAD}$ ). The values are more contrasting when the engine was operated at $60 \%$ engine load with a constant engine speed of $2500 \mathrm{rpm}$. It can be seen that the conventional diesel showed more concentration on the frequency distributions of Pmax corresponding to CAD. This combustion phasing 
parameter indicates that the diesel engine is more stable when operating with conventional diesel compared to palm biodiesel, especially at high engine load. Figure 8 presents the cyclic variations of IMEP for conventional diesel and palm biodiesel at 200 consecutive cycles with the engine operating at $2500 \mathrm{rpm}$ under various load conditions. It is apparent from these figures that the test fuels directly affected the IMEP ratings with IMEP for palm biodiesel are consistently higher compared to the conventional diesel at various engine loads.

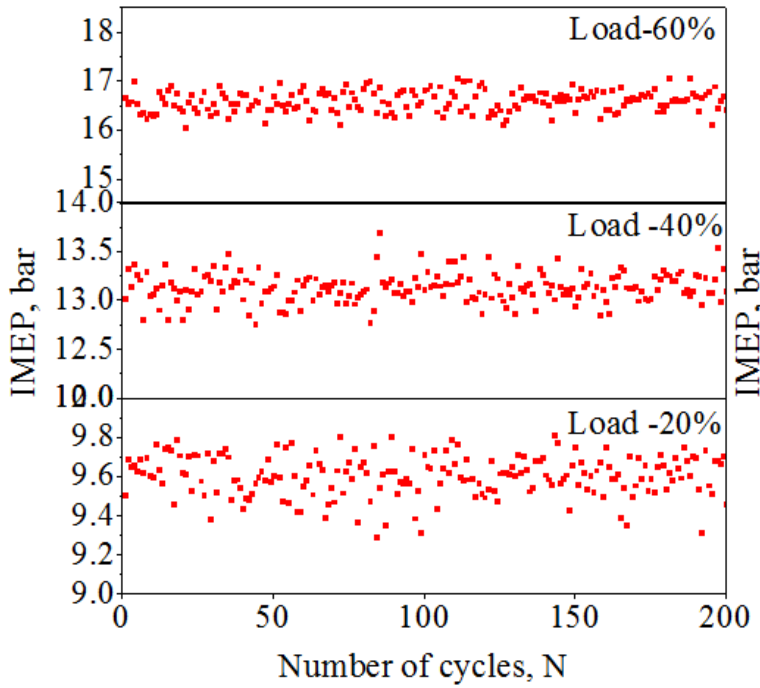

(a)

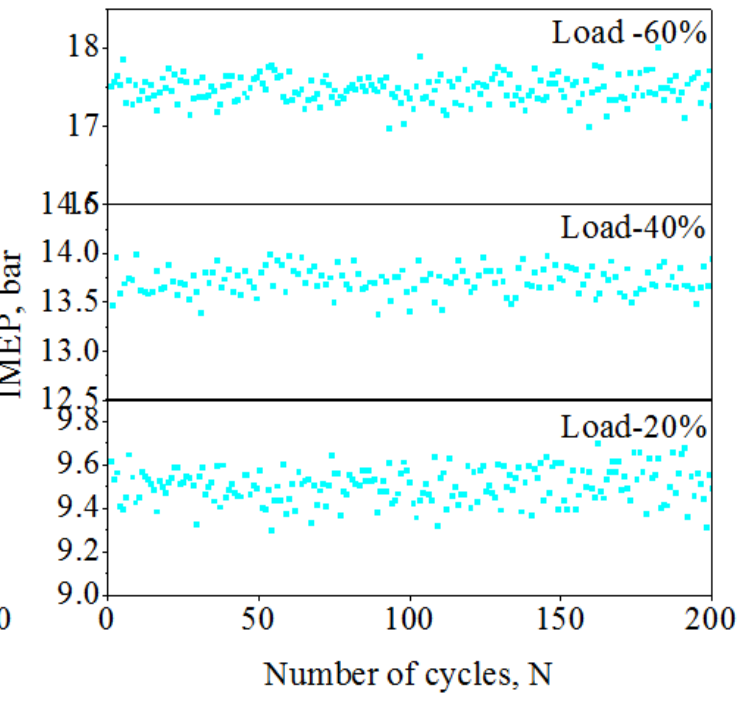

(b)

Figure 8. IMEP cyclic variations for (a) conventional diesel and (b) palm biodiesel.

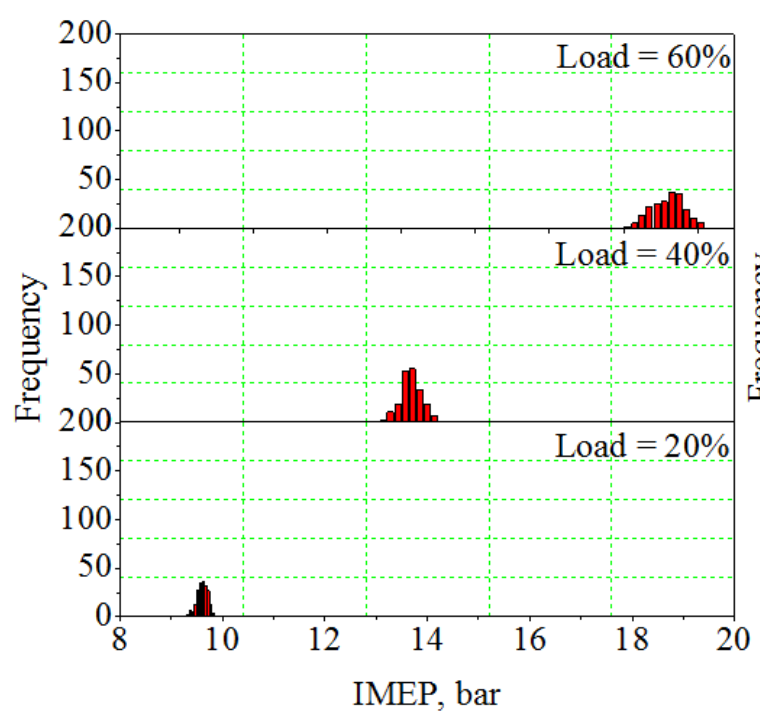

(a)

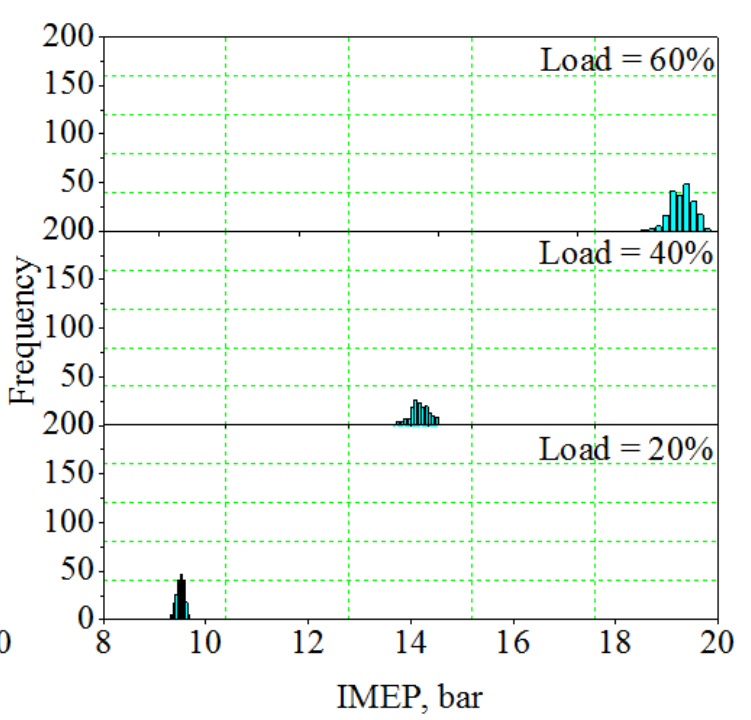

(b)

Figure 9 Frequency distributions of IMEP for (a) conventional diesel and (b) palm biodiesel.

This expected condition is mostly related to the maximum cylinder pressure of the test fuels. It can be noticed from these figures that the cyclic variations of IMEP for palm biodiesel is lower compared to the conventional diesel with a minimum IMEP value of 
9.3 bars while the maximum IMEP value is 9.7 bars at engine load of $20 \%$. While for conventional diesel, the maximum and minimum values for IMEP are 9.8 bars and 9.3 bars respectively. However, cyclic variations of IMEP for palm biodiesel increase rapidly compared to the conventional diesel at engine loads of 40 and $60 \%$. Maximum IMEP values for palm biodiesel at 40 and $60 \%$ engine loads are 14 and 18 bars which are 2.1 and 5.3\% higher compared to conventional diesel (13.7 and 17.1 bars). While for minimum IMEP values at 40 and $60 \%$ engine loads, conventional diesel produced 4.6 and $5.4 \%$ lower (12.8 and 16.1 bars) compared with palm biodiesel (13.4 and 17 bars). The frequency distributions of IMEP for diesel and palm biodiesel corresponding to 200 consecutive cycles are shown in Figure 9. It can be noticed from these figures that the IMEP variations for both test fuels increased from 20, 40 and $60 \%$ engine loads corresponding to 200 consecutive cycles. It is observed that the IMEP ranges for conventional diesel at 20 and $40 \%$ engine load are similar to palm biodiesel. However, at $60 \%$ engine load, the frequency distributions of IMEP for conventional diesel are more tabularized compared to palm biodiesel. It can be described from these figures that higher IMEP concentration occurs for conventional diesel compared to palm biodiesel along 200 consecutive cycles at $20 \%$ engine load. While for $40 \%$ engine load, palm biodiesel has higher IMEP concentration in contrast to the conventional diesel.

\section{CONCLUSIONS}

This paper experimentally investigated the cyclic variation of the combustion parameters; indicated mean effective pressure and maximum cylinder pressure of palm biodiesel and conventional diesel as a baseline fuel, operating under specific engine loads (20, 40 and $60 \%)$ at a constant engine speed $(2500 \mathrm{rpm})$ with 200 cycles. The overall results show that palm biodiesel statistically tends to achieve higher Pmax but lower IMEP when compared to conventional diesel at higher engine loads. It was found that the frequency distributions for Pmax and conventional diesel are scattered at higher engine load. This study is related to the engine cyclic variations, which is identified as a fundamental and complex engine problem that contributes to the limitation of lean mixtures, a decrease in engine power, poor driveability and may increase the engine noise and vibration. Furthermore, additional different fuels with dissimilar fuel properties used in diesel engines besides conventional diesel are other interesting topics for the advanced study. It can be concluded that the fuel properties of palm biodiesel have influenced most of the combustion parameters in the diesel engine.

\section{ACKNOWLEDGEMENTS}

The authors would like to thank the Department of Polytechnic Education, Ministry of Higher Education Malaysia and Universiti Malaysia Pahang for providing laboratory facilities and financial assistance under its specific research grant, RDU 150388.

\section{REFERENCES}

[1] Aydin S, Sayin C, Aydin H. Investigation of the usability of biodiesel obtained from residual frying oil in a diesel engine with thermal barrier coating. Applied Thermal Engineering. 2015;80:212-9. 
[2] Abu-Hamdeh NH, Alnefaie KA. A comparative study of almond and palm oils as two bio-diesel fuels for diesel engine in terms of emissions and performance. Fuel. 2015;150:318-24.

[3] Yu L, Ge Y, Tan J, He C, Wang X, Liu H, et al. Experimental investigation of the impact of biodiesel on the combustion and emission characteristics of a heavy duty diesel engine at various altitudes. Fuel. 2014;115:220-6.

[4] Barrios CC, Domínguez-Sáez A, Martín C, Álvarez P. Effects of animal fat based biodiesel on a TDI diesel engine performance, combustion characteristics and particle number and size distribution emissions. Fuel. 2014;117:618-23.

[5] Said NH, Ani FN, Said MFM. Review of the production of biodiesel from waste cooking oil using solid catalysts. Journal of Mechanical Engineering and Sciences. 2015;8:1302-11.

[6] Yasin MHM, Mamat R, Sharma K, Yusop AF. Influence of palm methyl ester (PME) as an alternative fuel in multicylinder diesel engine. Journal Mechanical Engineering and Sciences. 2012;3:331-9.

[7] Lahane S, Subramanian K. Effect of different percentages of biodiesel-diesel blends on injection, spray, combustion, performance, and emission characteristics of a diesel engine. Fuel. 2015;139:537-45.

[8] Gülüm M, Bilgin A. Density, flash point and heating value variations of corn oil biodiesel-diesel fuel blends. Fuel Processing Technology. 2015;134:456-64.

[9] Broatch A, Tormos B, Olmeda P, Novella R. Impact of biodiesel fuel on cold starting of automotive direct injection diesel engines. Energy. 2014;73:653-60.

[10] Yusaf T, Hamawand I, Baker P, Najafi G. The effect of methanol-diesel blended ratio on CI engine performance. International Journal of Automotive and Mechanical Engineering. 2013;8:1385-95.

[11] Kumaran P, Gopinathan M, Kantharrajan S. Combustion characteristics of improved biodiesel in diffusion burner. International Journal of Automotive and Mechanical Engineering. 2014;10:2112-21.

[12] Azman SR, Ismail M, Kadhum AAH, Yaakob Z. The performance of monolithic structured calcium oxide for biodiesel. International Journal of Automotive and Mechanical Engineering. 2014;10:1959-70.

[13] Rahim R, Mamat R, Taib MY, Abdullah AA. Influence of fuel temperature on a diesel engine performance operating with biodiesel blended. Journal of Mechanical Engineering and Sciences. 2012;2:226-36.

[14] Vashist D, Ahmad M. Statistical analysis of diesel engine performance for castor and jatropha biodiesel-blended fuel. International Journal of Automotive and Mechanical Engineering. 2014;10:2155-69.

[15] Soon LB, M. Rus AZ, Hasan S. Continuous Biodiesel Production using Ultrasound Clamp on Tubular Reactor. International Journal of Automotive and Mechanical Engineering. 2013;8:1396-405.

[16] Khalid A, Jaat N, Sapit A, Razali A, Manshoor B, Zaman I, et al. Performance and emissions characteristics of crude jatropha oil biodiesel blends in a diesel engine. International Journal of Automotive and Mechanical Engineering. 2015;11:2447-57.

[17] Hasan MM, Rahman MM, Kadirgama K. A Review on homogeneous charge compression ignition engine performance using biodiesel-diesel blend as a fuel. International Journal of Automotive and Mechanical Engineering. 2015;11:2199211. 
[18] Rostami S, Ghobadian B, Kiani Deh Kiani M. Effect of the injection timing on the performance of a diesel engine using diesel-biodiesel blends. International Journal of Automotive and Mechanical Engineering. 2014;10:1945-58.

[19] Azman SR, Ismail M, Kadhum AAH, Yaakob Z. The performance of monolithic structured calcium oxide for biodiesel. International Journal of Automotive and Mechanical Engineering. 2014;10:1959-70.

[20] Abbaszadeh A, Ghobadian B, Najafi G, Yusaf T. An experimental investigation of the effective parameters on wet washing of biodiesel purification. International Journal of Automotive and Mechanical Engineering. 2014;9:1525-37.

[21] Abedin M, Masjuki H, Kalam M, Sanjid A, Rahman SA, Fattah IR. Performance, emissions, and heat losses of palm and jatropha biodiesel blends in a diesel engine. Industrial Crops and Products. 2014;59:96-104.

[22] Palash S, Kalam M, Masjuki H, Masum B, Fattah IR, Mofijur M. Impacts of biodiesel combustion on NO $\mathrm{x}$ emissions and their reduction approaches. Renewable and Sustainable Energy Reviews. 2013;23:473-90.

[23] Özener O, Yüksek L, Ergenç AT, Özkan M. Effects of soybean biodiesel on a DI diesel engine performance, emission and combustion characteristics. Fuel. 2014;115:875-83.

[24] Behçet R, Oktay H, Çakmak A, Aydin H. Comparison of exhaust emissions of biodiesel-diesel fuel blends produced from animal fats. Renewable and Sustainable Energy Reviews. 2015;46:157-65.

[25] Yusop A, Mamat R, Mat Yasin M, Ali OM. Effects of particulate matter emissions of diesel engine using diesel-methanol blends. Journal of Mechanical Engineering and Sciences. 2014;6:959-67.

[26] Adam IK, A. Aziz AR, Yusup S. Determination of diesel engine performance fueled biodiesel (rubber seed/palm oil mixture) diesel blend. International Journal of Automotive and Mechanical Engineering. 2015;11:2675-85.

[27] Ghobadian B, Najafi G, Nayebi M. A Semi-empirical model to predict diesel engine combustion parameters. Journal of Mechanical Engineering and Sciences. 2013;4:373-82.

[28] Abdullah NR, Shahruddin NS, Mamat R, Ihsan Mamat AM, Zulkifli A. Effects of Air Intake Pressure on the Engine Performance, Fuel Economy and Exhaust Emissions of A Small Gasoline Engine. Journal of Mechanical Engineering and Sciences. 2014;6:949-58.

[29] Ali OM, Mamat R, Abdullah NR, Abdullah AA. Analysis of blended fuel properties and engine performance with palm biodiesel-diesel blended fuel. Renewable Energy. 2016;86:59-67.

[30] Iqbal MA, Varman M, Hassan MH, Kalam MA, Hossain S, Sayeed I. Tailoring fuel properties using jatropha, palm and coconut biodiesel to improve CI engine performance and emission characteristics. Journal of Cleaner Production. 2015;101:262-70.

[31] Yasin M, Mamat R, Abdullah A, Abdullah N, Wyszynski M. Cycle-to-cycle variations of a diesel engine operating with palm biodiesel. Journal of KONES. 2013;20:443--50.

[32] Li L, Wang Z, Gong C, Deng B, Xiao Z, Wang H. Investigation of cold-start based on cycle-by-cycle control strategy in an EFI LPG engine. SAE Technical Paper; 2004. 
[33] Maurya RK, Agarwal AK. Experimental investigation of cyclic variations in HCCI combustion parameters for gasoline like fuels using statistical methods. Applied Energy. 2013;111:310-23.

[34] Mat Yasin MH, Mamat R, Yusop AF, Rahim R, Aziz A, Shah LA. Fuel physical characteristics of biodiesel blend fuels with alcohol as additives. Procedia Engineering. 2013;53:701-6.

[35] Reyes M, Melgar A, Pérez A, Giménez B. Study of the cycle-to-cycle variations of an internal combustion engine fuelled with natural gas/hydrogen blends from the diagnosis of combustion pressure. International Journal of Hydrogen Energy. 2013;38:15477-87.

[36] Pham PX, Bodisco TA, Ristovski ZD, Brown RJ, Masri AR. The influence of fatty acid methyl ester profiles on inter-cycle variability in a heavy duty compression ignition engine. Fuel. 2014;116:140-50.

[37] Maurya RK, Saxena MR, Akhil N. Experimental investigation of cyclic variation in a diesel engine using wavelets. In: Berretti S TS, Srivastava PR, editor. Intelligent Systems Technologies and Applications: Springer International Publishing; 2016. p. 247-57.

[38] Aleiferis PG, Taylor AM, Whitelaw JH, Ishii K, Urata Y. Cyclic variations of initial flame kernel growth in a Honda VTEC-E lean-burn spark-ignition engine. SAE Technical Paper; 2000.

[39] Ibrahim MM, Ramesh A. Investigations on the effects of intake temperature and charge dilution in a hydrogen fueled HCCI engine. International Journal of Hydrogen Energy. 2014;39:14097-108. 